\title{
Employability of Graduates of Sri Lankan Universities
}

\author{
R. G. Ariyawansa \\ Department of Estate Management and Valuation \\ University of Sri Jayewardenepura \\ E-mail: ariyaw71@hotmail.com
}

\begin{abstract}
The aim of this paper is to review determinants of graduates' employability of Sri Lankan universities. As the education is a major criterion of measuring the development of a country and many Sri Lankan families give higher priority for their children's education, it is important to realize the problem of graduate employability of the country. This study reviewed available literature to comprehend different views relating to the issue in general. Primary data was collected through discussions and telephone conversations with managers in government sector, private sector and non-government organizations. Also an examination of a random sample of 50 newspaper advertisements of job opportunities in weekend news papers was made. Further, the study used quality assurance judgement review results relating to the degree programs in Sri Lankan universities conducted by Sri Lanka Quality Assurance Council. It is found that there are many jobs for engineering/science and management graduates in current job market and fewer opportunities are available for humanities and social sciences. However, as far as quality of degree programs is concerned humanities and social sciences degree programs are better than even some degree programs offered by medical faculties in Sri Lanka.
\end{abstract}

Key words: Determinants of Employability, Graduates' Employability, Job Market, Quality Assurance

\section{Introduction}

Education is a major criterion of measuring the development of a country. It is also a key determinant of the wealth and prosperity of a nation. One of the main objectives of the education, particularly of higher education, is to prepare students to pursue different careers in a country. University education is the core of the higher education. Universities are supposed to be social institutions which provide facilities for higher intellectual needs of a community as regards both academic knowledge and professional training. Therefore, it has to respond to the social aspirations for higher education and be responsive to social changes according to the Economic Review (1983). Newman (1974) as in Senadeera (1997) defines university as an institute, which teaches the entire knowledge and spreads the knowledge. Ballantine (1997) describes universities as communities with overall academic programs, centralized physical settings, a form of governance and a range of services. 
Hommadi (1990) identifies multiple duties of universities which help to reach the above objectives such as "conduct pure and applied research", "protect the knowledge", "exchange the knowledge", "protect the culture", "solve the social problems as a public service", "help for the modernization", "train the students for the academic and professional sectors", "improve students' thinking skills, physical strength, control emotional feelings, obey the requirements, and enhance the brainpower", "Improve students' requirements such as food, accommodation, medical facilities, guidance and finally the job opportunities". Accordingly, it is clear, that the "employability of graduates" is a highly expected function of a university.

It is said that the major objective of promoting children for higher education in most of Sri Lankan families is to ensure their employability (Perera, 2008; Perera, 2005). Accordingly, almost all Sri Lankan families are having greater aspiration of providing university education for their children as a secured path of higher employability. Generally, graduates are considered as one of the most important human capital in a country. They are expected to work in a middle or top management level providing services to society in various ways. Therefore, in Sri Lanka, there is a considerable demand for higher education. Hence, obtaining a place in a national university is a great challenge for students. However, many students, who are fortunate to enter the universities, have to face numerous challenges especially at the end of the graduation in seeking suitable employments.

The recent experience reveals that even talented graduates have to wait for a long time to be employed after the graduation. Some of graduates including Management graduates are waiting to be employed by government recruitment schemes (Wickramarachchi, 2008). Many of the graduates having passed out obtain a certificate, which does not help enough them to find suitable employments. Even if one of the main objectives of the university education is to improve the skills of students to face the challenges in external society, they have to leave from the university without having sufficient self-confidence and assurance for better employments (De Silva, 1977). Under this circumstance, graduates' unemployment has become a severe problem in Sri Lanka during the last few decades.

In many situations, the reality is that the qualification along does not help enough to find a job because of the mismatch between the demand and the supply of the job market. Therefore, some graduates have to be engaged in irrelevant jobs mostly under low salaries while some of them have to be unemployed and waiting for a long time mostly until the government provides opportunities. Such graduates will become a burden not only for their families but also to the whole country. The effects of this would be arisen as frustration, youth unrest, violence, and other forms of anti-social behaviours. Furthermore, consequences of this would be prevailing in society as short term or/and long term social, cultural, economic, demographic and political issues.

Within this context, it is important to identify why graduates can not find suitable jobs as soon as they pass out from universities. And why is the country's employment sector not capable to absorb such graduates into the development process? Therefore, the main 
objective of this paper is to discuss different views over the employability of graduates of Sri Lankan Universities with special focus on graduates in Social Sciences and Management.

\section{Methodology}

In order to address the issue of employability of graduates of Sri Lankan Universities, two views i.e. "level of competencies of graduates developed by degree programs" and the "employers' requirements from a graduate" were taken into consideration.

Two methods were applied to collect data relating to "employers' requirements from a graduate". Discussions and telephone conversations with managers in government sector, private sector and non-government organizations were made as one method. In addition, examination of a random sample of 50 newspaper advertisements in weekend news papers regarding employment opportunities for graduates was done as an alternative method of secondary data collection.

To collect necessary data regarding "level of competencies of graduates developed by degree programs", this study totally depended on secondary data from reports of the University Grants Commission, Quality Assurance Council of Sri Lanka, and other institutions, as well as books and journals etc. Different views were descriptively analyzed with a view to comprehend the magnitude of the issue

\section{The Main Expectations of University Education}

Sri Lankan University education system is also influenced by the global university system and it has been organised according to the international standards to a certain extent in some areas. From the beginning, the main objective of the Sri Lanka university education is "to give a higher education and expand the knowledge and intelligence" (State Council of Sri Lanka, 1942). In Adikaram's words "university education should aim at developing all aspects of human life as an essential task".

Sri Lanka Universities Act 1978 indicates that "university is established for the purpose of providing, promoting and developing higher education" (University Act No.16, 1978). According to the report of 1984 -1988 of University Grant Commission, "any definition with regard to the objectives of university education would not be accepted in global level. Accordingly Sri Lankan university education aims to provide a critical knowledge of the society where students are living and working. The target of the university is to encourage the student to explore the authenticity. At the end of university education, students should be "productive persons" economically as well as socially, and it will also ensure a "great satisfaction" of students, university and the entire society at large according to the Economic Review (1997).

The above definition provides a broader meaning for the ultimate objective of the university education. Especially, it has emphasised the "productivity of graduates" as an

1 This is cited from the convocation address of the University of Sri Jayewardenepura in 1979 made by Dr. E.W. Adikaram, published by the Dr. E.W. Adikaram Foundation, Colombo (2005). 
expected outcome of universities and also the "overall satisfaction" with regard to the end results. Hence, it can be argued that the "employability objective" is strongly embedded in the concepts of "productivity" and "greater satisfaction of students" even though the term "employability" is not indicated.

Even though the Sri Lankan university education is not a job oriented system, in practical context, students as well as all stakeholders of the university system highly expect better employment opportunities for students at the end of graduation. On the other hand, the objectives of university education directly emphasize a "leading role from graduates" in different scales for the country's development. Therefore, for the development, countries highly rely on its valuable human resources particularly the essence of fresh intellectuals who are known as "university graduates". Hence, it can be argued that one of the universities' main obligations is to produce talented and competent graduates suitable for the development process of the country.

However, the public opinion over the Sri Lankan university education system is that universities are not producing suitable graduates especially in the area of Social Sciences including Management. Since the economy has been unable to absorb graduates into the development process smoothly during the last few decades, it was needed to implement special massive recruitment schemes by the governments (Wickramarachchi, 2008). The general opinion of educationalists as well as employers is that the economic system of the country is not being able to absorb its graduates to the development of the country because of the less relevancy and quality of degree programs. This situation is critical among graduates of Social Sciences and Humanities and some Management programs.

According to journal of Economic Review, (1997) many subjects of Arts, Social Sciences and Humanities are not sufficient and relevant to fulfil the demand of job market or to improve necessary skills to contribute for the development. Further, the traditional subjects have not been modified according to the demand of the current job market. On one hand, thousands of students expect to enter to universities annually to have education in Arts, Humanities and Social Sciences stream, which are not directly relevant for their employment aspirations. This may happen due to limited as well as conventional options available in the higher education institutes of social sciences for such students. On the other hand the modifications to the syllabuses and structures of degree programs to meet the changing needs of the job markets may radically deviate the main objective of university education. For instance, if universities have to give more attention to develop students' basic IT skills and English proficiency etc, students may have to lose some essential components in their degree programs. Therefore, conflicts can be seen between the pedagogical goals of the university education and the reality of the economy when analysing the graduates' employability issue.

\section{Employability of Graduates at Present}

There are several other dimensions of this problem, which are common for social sciences as well as other areas. Lack of professional orientation is one problem relating to the employability. Generally, Medicine, Engineering, Law, Agriculture, Science and Management faculties guide their students towards properly defined objectives of 
professions. For instance, degree programs in management faculties such as Business Administration, Finance, Accounting, Human Resource Management, Estate Management and Valuation, Marketing etc. are having links with professional bodies nationally and some possibilities of international links. Through such links, students can develop their future career plans and necessary talents.

What are the occupational expectations of students of Arts, Humanities and Social Sciences? To a greater extent, unemployment rate is high among the Arts graduates (University Grants Commission, 2004; Southern Provincial Council, 1999; Senadeera, 1999; De Silva, 1977) and to some extent among Management and Commerce graduates (Wickramarachchi, 2008). Therefore, comparatively, the occupational expectation of graduates of Humanities and Social Sciences has become an issue. Within this context, the greatest challenge of the universities in today is to improve the quality and relevancy of the education according to the changing demands of the job market (Wickramarachchi, 2008).

Zears' report (1971) and Higher Education Reform Committee in Sri Lanka (in Gunawardana, 1997) explain the relationship between education and employment. Accordingly, during 1970's, it was proposed to establish "job oriented courses" such as Estate Management and Valuation, Finance and Taxation, Journalism etc. Generally, the graduates who followed job oriented courses such as Law, Medicine, Engineering, Architecture, Valuation, and Accountancy etc. could find jobs without having a longer waiting time comparatively to the other degree holders especially in the areas of Social Sciences and Humanities.

The starting of job oriented courses creates career expectations among students. However, to provide training and relevant education for particular jobs etc. is a meaningful attempt only if the expected employment opportunities are created in the market. Therefore, it is argued that the diversification of university courses into new pathways is only meaningful if they are in the line with the national development plans (De Silva, 1977). On the other hand, job oriented courses may have highly specialized features and thereby such graduates are at risk of having the least employability options. For instance, Medical graduates have only one career option. They are successful until the government is ready to recruit them to the government hospitals. However, competent Management or Arts graduates have a wide range of career options if they are capable to accept challenges.

A study conducted by Southern Provincial Council in Sri Lanka on "Unemployed Graduates" in 1999 shows that there were 1431 unemployed graduates in Southern province. Out of them, 1072 (71\%) were BA graduates. University Grants Commission (2004) also conducted a survey on the same theme and found out that unemployment rate of BA graduates had been 63\% of total unemployed graduates. De Silva (1977) indicates, that "particularly Arts graduates have to face more troubles than the other graduates". A higher number of Arts students are graduated annually and due to excess of graduates according to the country's requirement, the graduate unemployment problem was started. Under this context, it seems that the university system has been amplifying the 
unemployment problem of the country. Criticising the responsibility of university system regarding graduates employability, De Silva (1977) further mentioned that it has tried to respond by hastily conceived ad-hoc solutions which have only aggravated the situation.

\section{Attitudes of the Graduates}

Not only due to the problems of the education system but attitudes of graduates also affect on the unemployment problem (Hettige, 2000). The Presidential Committee appointed to identify problems of the university system revealed that there are three main reasons for the graduates' unemployment problem such as; "negative attitudes", "lack of communication skills", and "lack of English knowledge" (Ministry of Education and Higher Education, 1995).

By now, most of degree programs in Management streams have widely been modified and the mode of delivery of lectures including conversion of the medium of instruction into English has shown a progress of employability (Wickramarachchi, 2008). However, as far as the attitudinal issues are concerned both the universities and the economic policies are lacking behind. Graduates generally expect "government jobs", "pensionable jobs", "higher salary from the beginning", "higher position at the beginning" etc. from employers.

As far as the "position" and the "reputation" are concerned, finding a job will be a big problem to graduates. As Hugh et al (1992) emphasised, as the other economics, Sri Lanka is also expanding medium and small-scale firms widely, which provide more job opportunities, however, graduates prefer to find big institutes. Hence, attitudinal changes in graduates as well as general public will only eliminate this negative practice.

In general, jobs are available either in government sector or non-government organizations or in private sector institutions. However, the majority of graduates prefer to join with the government sector only. The availability of jobs for graduates in the government sector institutions in Sri Lanka heavily depends on the state policies adopted by particular political party which is in power. Though the current situation is somewhat positive in this regard, general trend is shrinking of job opportunities for graduates in the public sector. Pensionable jobs are rare among newly formed job opportunities. And also available jobs are challenging, need to be self-motivated to gain more benefits and to reach a higher position especially in the private sector. Hence, there is a significant contradiction between graduates' career expectations and the available opportunities.

Sri Lankan society also generally expects that graduates must have high and reputable occupations. Such deeply rooted norms and values in the society discourage graduates to start a job at a lower level. Also a growing societal attitude regarding some indigenous development sectors as agricultural sector badly affects on the possibility of absorbing graduates into some areas such as agro-based occupations and self-employments etc. As an agricultural country such attitudes adversely affect not only to shrink the graduates' job opportunities but also to the economic development of the country. Therefore, as Wickramarachci (2008) has emphasized, strategies should be made to produce "managers" and "entrepreneurs" to reduce the employability problem. However, it can be 
pointed out that it is unable unless such strategies are incorporated with suitable mechanisms for attitudinal changes as well.

\section{Employers' Requirements from a Graduate}

Coldstream (1991) pointed out the communication and teamwork skills as some of the employers' expected characteristics of graduates. Strobart (1991) mentioned broad skills such as analytical, creativity, mathematical knowledge, literacy, motivation and leadership qualities of graduates are considerable factors in job market (in Gunawardena 1997). For the private sector employments manual/social/intellectual skills, knowledge, understanding and attitudes are some requirements (Cole, 1993).

According to some studies in the UK, employers are considering more about varieties of skills than the speciality. British industrial and commercial fields need graduates who possess various skills and adoptability (CIHE, 1987 as in Gunawardena 1997). According to a study conducted among 52 business institutions, $90 \%$ of them pointed out that most important quality of a graduate is communication skill. Except that, Quality of Higher Education study has identified some other important characteristics such as subject knowledge, research and analytical ability, inter personal relations, problem solving, self confidence, self management, decision making and judgement skills etc. The other virtues and skills that are expected from graduates are, genuineness, humbleness, obedience, credibility, tactfulness, sensitiveness, cooperation, devotion, active, straightness, unchangeable, altruistic, new thinking, leadership, strength, organizational skills, time management, skills of discussion, commercial knowledge and personality etc. (Gunawardena, 1997).

Additionally, English proficiency, and IT skills, etc. have been critical determinants of graduates' employability in Sri Lankan organizations (Ariyawansa and Perera, 2005). Further, Gunawardena (1991) conducted a study about the relationship between education and employment opportunities among 93 representatives of states, semi state and private sector in Sri Lanka. It has questioned that what factors are considered by employers when selecting a graduate. Proving the result of the British study, the highest rate $(34 \%)$ of the respondents have pointed out that communication skills is the mostly expected skill in selecting graduates for employments. The other highlighted qualities are external appearance, manners, ethics, personality, respect to others, team work ability, interpersonal skills, leadership etc. In addition, $66.7 \%$ of government sector employers and $89.6 \%$ of private sector employers have emphasized the importance of proficiency of English language.

Further highlighting the studies conducted by Chamber of Commerce (1999) and Gunawardana's survey (1991), Hettige (2000) explains some attributes such as the ability to lead a team and ability to achieve results in a short period, ability to prioritise/ organize time productively, openness, positive thinking, practical mind set, willing to learn from a cross section of people, general knowledge including world affaires, wide interest, personal grooming and business etiquette are also determinants of graduates employability. It can be argued that these characteristics cannot be developed by conventional teaching learning and evaluation methods. 


\section{Available Jobs and Requirements in the Current Market}

It is also important to review employers' point of views on job requirements for currently available opportunities. This survey applied two main strategies to find such data as news paper advertisements and telephone discussions with employers.

Table: 1 Available Jobs and job Requirements: Summary of the Survey

\begin{tabular}{|l||c||l||c||}
\hline Job sector/expected graduates & $\%$ & \multicolumn{1}{|c|}{ Needed requirements } & \% \\
\hline \hline Government & 7 & IT skill/computer skills & 42 \\
\hline Private & 78 & English/communication skills & 63 \\
\hline NGO & 15 & Training/experience & 73 \\
\hline Arts & 9 & Leadership/decision making & 21 \\
\hline Management/ Commerce & 39 & Team work/Interpersonal skills & 45 \\
\hline Science/Engineering & 52 & Problem solving/Analytical skills & 21 \\
\hline
\end{tabular}

Source: Survey data 2007/2008

Even though, most of the graduates expect government jobs, according to the paper advertisements there are many jobs in private sector and NGOs that are $78 \%$ and $15 \%$ respectively in the sample. These figures are evident for the nature of reducing opportunities of government sector and expanding opportunities in private sector in the country. The other significant finding is that the majority of job opportunities are for Science/ Engineering and Management/Commerce graduates. Out of the examined total job opportunities $52 \%$ are for Science/Engineering graduates and $39 \%$ for Management/Commerce graduates. This data will substantiate that there are less job opportunities in current job market for areas of Social Sciences and Humanities graduates compared with the other graduates.

Training/experience $(73 \%)$ is the highly required factor in the job market. However, without having considerable links with the study programs and stakeholders it is not easy to have experience or training for graduates. On the other hand proficiency of English (63\%) and IT skills (42\%) are also considerable requirements in the job market. Most of Management and Science/Engineering degree programs are conducted in English medium. Therefore, students have opportunities and they are compelled to develop English proficiency. Conducting degree programs in English medium may generate some difficulties for students and staff that anyhow can be minimized. However, since most of Arts and Social Sciences degree programs are conducted in Sinhala medium and provide facilities for learning English separately, students' interest of developing English proficiency is seemingly poor. Therefore, these students are comparatively less capable in English proficiency.

Further, team work/interpersonal relations (45\%), is also considerable factor in the job market. Except these, leadership qualities, and especially problem solving and analytical ability, are the other highly demanded requirements of the current job market. Graduates must have additional skills such as leadership qualities, team work/interpersonal relations and especially problem solving and analytical ability, which are highly concerned in the job market. 
Even though the problem of graduates' unemployment is partially a result of economic development, the society tends to perceive it as a result of quality of the operations of the university system. Accordingly, the main problem for the graduates' unemployment relates with the quality and the relevancy of the degree programs. Therefore, the Sri Lanka universities are now seriously encouraged to evaluate the level of relevancy and quality of degree programs as a national education policy (www.qacouncil.lk 30.11.2008).

\section{Quality and Relevancy of Degree Programs in Sri Lanka}

In order to upgrade the standards of degree programs available in Sri Lanka, it is compulsory for all higher education programs to be judged by Quality Assurance Subject Reviewers appointed by the Quality Assurance Council of Sri Lanka. This emphasises the quality and relevancy of degree programs under eight (08) inter-related aspects as indicated in the following Table.

Table: 2 Quality Assurance Aspects

\begin{tabular}{|l|l|l||}
\hline No & Quality Assurance Aspect & Description \\
\hline \hline 1 & $\begin{array}{l}\text { Curriculum Design, Content } \\
\text { and Review }\end{array}$ & $\begin{array}{l}\text { Aim and objectives of the program, learning } \\
\text { outcomes, adequateness of contents and } \\
\text { relevancy with the expected learning outcome, } \\
\text { and timely revisions etc are reviewed }\end{array}$ \\
\hline 2 & $\begin{array}{l}\text { Teaching, Learning and } \\
\text { Assessment Methods } \\
\text { appropriateness of teaching, learning and } \\
\text { outcomes is judged }\end{array}$ \\
\hline 3 & $\begin{array}{l}\text { Extend and Use of Student } \\
\text { Feedback }\end{array}$ & $\begin{array}{l}\text { How effectively students are engaged in the } \\
\text { learning process is judged by the degree of using } \\
\text { students' feedback in achieving the set learning } \\
\text { outcomes of the degree program }\end{array}$ \\
\hline 4 & Postgraduate Studies & $\begin{array}{l}\text { Postgraduate level experience of the department, } \\
\text { staff, and quality postgraduate programs offered } \\
\text { by the department are evaluated }\end{array}$ \\
\hline 5 & $\begin{array}{l}\text { Quality of Students Including } \\
\text { Students Performance and } \\
\text { Progression }\end{array}$ & $\begin{array}{l}\text { Qualification of students, selection procedures, } \\
\text { Z-Scores, continual progresses along with the } \\
\text { degree program, pass rate, classes, dropout rate } \\
\text { etc. are judged }\end{array}$ \\
\hline 6 & Peer Observation & $\begin{array}{l}\text { This mainly evaluates the level of quality of } \\
\text { teaching, teaching materials and evaluation } \\
\text { methods assured by staff members through the } \\
\text { assistance of peers }\end{array}$ \\
\hline 7 & $\begin{array}{l}\text { Relevancy and adequateness of components } \\
\text { available in the degree program to ensure the } \\
\text { necessary skills of students are judged }\end{array}$ \\
\hline \hline & $\begin{array}{l}\text { Overall support given for students to achieve } \\
\text { their educational goals by the } \\
\text { department/university etc. is judged }\end{array}$ \\
\hline
\end{tabular}

Source: Author compiled the Table using the information from www.quaacouncil.lk (accessed on 30.11.2008) 
The description of the above Table clearly implies that all the quality judgement aspects are inter-related and aimed at quality output from degree programs. Up to date 175 Subject/Programme Review Assessments have been conducted (www.quaacouncil.lk 30.11.2008). According to the evaluated results, the Quality Assurance Council reveals that universities/departments are weak in six (06) aspects, namely "Curriculum Design, Content and Review", "Extend and Use of Student Feedback", "Postgraduate Studies", "Peer Observation", "Skills Development', and "Academic Guidance and Counselling". Following Table indicates the summary of the result of review judgements for already evaluated degree programs.

Table: 3 Evaluated Quality Assurance Aspects in Degree Programs

\begin{tabular}{|c|c|c|c|c|c|}
\hline No & $\begin{array}{l}\text { Quality Assurance } \\
\text { Aspects }\end{array}$ & $\begin{array}{c}\text { Good } \\
(\%)\end{array}$ & $\begin{array}{l}\text { Satisfa- } \\
\text { ctory } \\
(\%)\end{array}$ & $\begin{array}{l}\text { Not } \\
\text { satisfa } \\
\text {-ctory } \\
(\%)\end{array}$ & Comments \\
\hline 1 & $\begin{array}{l}\text { Curriculum Design, } \\
\text { Content and Review }\end{array}$ & 65 & 34 & 01 & $\begin{array}{l}\text { Only } 01 \% \text { of the aspect is not } \\
\text { satisfactory in all evaluated } \\
\text { programs and a higher } \\
\text { percentage i.e. } 65 \% \text { is "good". }\end{array}$ \\
\hline 2 & $\begin{array}{l}\text { Teaching, Learning } \\
\text { and Assessment } \\
\text { Methods }\end{array}$ & 64 & 36 & - & $\begin{array}{l}\text { This aspect is stronger as none } \\
\text { of degree program is having a } \\
\text { single "not-satisfactory" } \\
\text { judgement }\end{array}$ \\
\hline 3 & $\begin{array}{l}\text { Quality of Students } \\
\text { Including Students } \\
\text { Performance and } \\
\text { Progression }\end{array}$ & 72 & 28 & - & $\begin{array}{l}\text { This aspect is the strongest } \\
\text { among all degree programs }\end{array}$ \\
\hline 4 & $\begin{array}{l}\text { Extent of Students } \\
\text { Feedback: Quality and } \\
\text { Quantitative }\end{array}$ & 43 & 51 & 06 & $\begin{array}{l}\text { A weak aspect since "Good" } \\
\text { judgements are less than } 50 \% \\
\text { and having } 6 \% \text { "not- } \\
\text { satisfactory" judgements }\end{array}$ \\
\hline 5 & Postgraduate Studies & 36 & 46 & 18 & $\begin{array}{l}\text { A weaker aspects in } 18 \% \text { of } \\
\text { programs and only } 36 \% \text { is good }\end{array}$ \\
\hline 6 & Peer Observation & 15 & 61 & 24 & The weakest aspect \\
\hline 7 & Skills Development & 58 & 41 & 01 & $\begin{array}{l}\text { This aspect is considerably } \\
\text { strong even though } 1 \% \text { of } \\
\text { programs are weak }\end{array}$ \\
\hline 8 & $\begin{array}{l}\text { Academic Guidance } \\
\text { and Counselling }\end{array}$ & 60 & 32 & 02 & $\begin{array}{l}\text { This aspect is considerably } \\
\text { strong even though } 2 \% \text { of } \\
\text { programs are weak }\end{array}$ \\
\hline
\end{tabular}

Source: Author compiled the Table using the data from www.quaacouncil.lk (accessed on 30.11.2008)

Only the aspects 02 and 03 as indicated in the above Table are stronger in all the evaluated degree programs as none of degree programs is weak in such aspects. At the same time, it is able to argue that aspects 01,07 and 08 are also strong even though some (less than 2\%) degree programs are weak, since a greater percentage of programs are 
good or satisfactory in those aspects. The aspect 04 is not at a critical stage and it is possible to improve easily as only $06 \%$ of evaluated programs are weak and $43 \%$ of programs are good in that aspect. However, the aspects 05 and 06 are at critical stage since around 1/5 and 1/4 of programs are weak in such aspects respectively. Only $36 \%$ and $15 \%$ programs are good in these aspects.

It is also possible to argue that the 05 and 06 aspects are less important and not critical in determining the quality and relevancy of undergraduate degree programs. Therefore, the impact of these aspects on the quality of degree programs can be ignored. This does not mean that these aspects are not important but the other aspects are more and directly important in determining the quality of undergraduate programs.

The above general picture can be examined deeply considering the program-wise judgements of evaluated degree programs. For that purpose, this study groups all the evaluated degree programs into five (05) disciplines as Medicine, Engineering, Science, Management, and Social Sciences. The classification is roughly based on the faculty-wise programs. As such, Medicine includes Medicine, Dental programs, and Veterinary programs. Science includes Bio-science, Physical-sciences and Agriculture. Engineering includes Architecture too. Management and Commerce is one category. All Social Sciences and Humanities are into one category. The following Table illustrates the evaluators' judgements for degree programs under these five disciplines.

Table: 4 Evaluation Judgements of Different Degree Programs

\begin{tabular}{|c|c|c|c|c|c|c|c|c|c|c|c|c|c|c|c|}
\hline \multirow{4}{*}{ 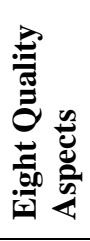 } & \multicolumn{15}{|c|}{ Degree Programs according to Major Disciplines } \\
\hline & \multirow{2}{*}{\multicolumn{3}{|c|}{$\begin{array}{c}\text { Medicine } \\
(26 \text { programs }) \\
\text { Evaluation } \\
\text { grades } \\
\end{array}$}} & \multirow{2}{*}{\multicolumn{3}{|c|}{$\begin{array}{c}\begin{array}{c}\text { Engineering } \\
(20 \text { programs })\end{array} \\
\begin{array}{c}\text { Evaluation } \\
\text { grades }\end{array} \\
\end{array}$}} & \multirow{2}{*}{\multicolumn{3}{|c|}{$\begin{array}{c}\text { Science } \\
\text { (59 } \text { programs }) \\
\begin{array}{c}\text { Evaluation } \\
\text { grades }\end{array}\end{array}$}} & \multirow{2}{*}{\multicolumn{3}{|c|}{$\begin{array}{c}\text { Management } \\
(18 \text { programs }) \\
\text { Evaluation } \\
\text { grades }\end{array}$}} & \multirow{2}{*}{\multicolumn{3}{|c|}{$\begin{array}{c}\begin{array}{c}\text { Social Sciences } \\
\text { (33 programs) }\end{array} \\
\begin{array}{c}\text { Evaluation } \\
\text { grades }\end{array} \\
\end{array}$}} \\
\hline & & & & & & & & & & & & & & & \\
\hline & $\mathbf{A}$ & $\mathbf{B}$ & $\mathbf{C}$ & $\mathbf{A}$ & $\mathbf{B}$ & $\mathbf{C}$ & $\mathbf{A}$ & $\mathbf{B}$ & $\mathbf{C}$ & $\mathbf{A}$ & $\mathbf{B}$ & $\mathbf{C}$ & $\mathbf{A}$ & $\mathbf{B}$ & $\mathbf{C}$ \\
\hline QA1 & 14 & 12 & - & 20 & 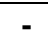 & - & 35 & 24 & 02 & 11 & 07 & 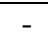 & 21 & 12 & 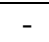 \\
\hline QA2 & 08 & 18 & - & 20 & - & - & 37 & 22 & - & 14 & 04 & - & 19 & 13 & - \\
\hline QA3 & 20 & 06 & - & 13 & 07 & - & 44 & 15 & - & 12 & 06 & - & 24 & 09 & - \\
\hline QA4 & 08 & 17 & 01 & 15 & 05 & - & 25 & 32 & 02 & 07 & 09 & - & 11 & 19 & 05 \\
\hline QA5 & 09 & 12 & 05 & 13 & 07 & - & 16 & 27 & 16 & 07 & 06 & 05 & 12 & 16 & 05 \\
\hline QA6 & 03 & 10 & 13 & 10 & 10 & - & 03 & 48 & 08 & 05 & 11 & 02 & 02 & 14 & 17 \\
\hline QA7 & 04 & 20 & 02 & 19 & 01 & - & 38 & 21 & - & 12 & 06 & - & 18 & 15 & - \\
\hline QA8 & 17 & 08 & 01 & 15 & 05 & - & 39 & 19 & 01 & 17 & 14 & 01 & 17 & 14 & 01 \\
\hline Total & 83 & 103 & 22 & 125 & 35 & - & 237 & 208 & 29 & 85 & 63 & 08 & 124 & 112 & 28 \\
\hline$\%$ & 39 & 50 & 11 & 78 & 22 & - & 50 & 44 & 06 & 54 & 40 & 05 & 47 & 42 & 11 \\
\hline
\end{tabular}

Source: Author compiled the Table based on the data from www.quaacouncil.lk (accessed on 30.11.2008) Notes:

(a) Eight Quality Aspects are the same as indicated in the Table 02

(b) $\mathrm{A}=$ Good, $\mathrm{B}=$ Satisfactory, $\mathrm{C}=$ Not satisfactory

The above summary very clearly indicates that all degree programs in the Engineering discipline are being performed well. All the quality aspects in such programs are the strongest among all degree programs in the country because none of the Engineering degree program has been evaluated as unsatisfactory under any aspect. And 78\% of judgements have been confirmed as "good", which is the highest percentage received. 
The other extreme end of the evaluation is the weakest discipline in terms of the percentage of unsatisfactory judgements over the eight quality aspects. According to the evaluated judgements, the highest percentage (11\%) of "unsatisfactory" judgments has been given for degree programs in the Medical discipline. Even the judgements as "good" for all eight quality aspects, degree programs in Medical discipline have received only $39 \%$ of judgements, which is the least percentage among all degree programs in Sri Lankan Universities. Then, degree programs in disciplines of Management, Science, and Social Sciences are being performed better than degree programs in Medical discipline respectively.

\section{Employability, Quality and Relevance of Degree Programs}

The necessity of having quality assurance for Sri Lankan degree programs has been stressed mainly due the issue of employability of graduates. As per the graduates' employability issue related literature as cited in the above paragraphs, there is an apparent argument that degree programs in Social Sciences and Humanities are poor in quality and relevancy, which is the key for the higher extent of unemployment among such graduates. Similarly, the existing literature has indirectly supported to develop a notion that the other degree programs are in higher level of quality and relevance and thereby such graduates are easily employable. However, quality assurance judgement results reveal a different scenario of the graduate employability issue. Accordingly, the quality and the relevancy are less important when the government provides employment opportunities.

\section{Concluding Remarks}

Even though graduates are highly valuable human resource of a country, most of them have to wait for a long time for suitable jobs. The mismatch between the degree and the demands of the job market as the main reason of this issue seems to be a conventional belief and seems as an invalid measure. Issues in the development of macro-economy of the country appear as a greater drawback in case of graduates' employability. The unemployment problem is especially critical among some areas in humanities and social science and some management graduates as a large number of students are graduated annually. It can be noticed that there are booming job opportunities for graduates in the private sector mainly for Science, Engineering, Management and Commerce graduates but lesser opportunities for Social Sciences and Humanities graduates.

Training/experience is a highly demanded factor in the job market especially, in the private sector. Proficiency of English language is a decisive factor. Further, there is a high demand for additional competencies such as IT skills, leadership qualities, analytical ability, team work and interpersonal relations along with a degree.

Development of basic IT skills and English proficiency should not be the responsibility of Universities. Such skills should be developed before entering the university. Since universities have adopted some strategies to improve these skills within the students, the major objectives of university education may not be fulfilled. If students are qualified 
with such basic skills when entering to the university, then it will be possible to train students providing necessary guidelines for the expected capacity development.

Quality assurance accreditation for degree programs of Sri Lankan Universities is a progressive policy initiative in ensuring competent graduates. However, the first round quality assurance judgement results show different dimensions of the graduates' employability. Accordingly, the following propositions can be made in connection with the problem for further discussions.

- If the government recruitment is limited or stopped, the biggest employability issue will be among the graduates in the Medical discipline not the other disciplines provided that the quality assurance judgements are highly reliable.

- If the economy is able to provide more jobs, Social Sciences graduates will find jobs easier than Medical graduates according to the quality assurance judgements.

- Quality assurance procedure for Sri Lankan universities does not evaluate degree programs accurately and, therefore, the judgement results do not present the reality.

\section{References}

Ariyawansa R. G. and Perera M. A. N. R. M. (2005), Determinants of Graduates Employability, Paper presented at the $10^{\text {th }}$ International Conference of Sri Lankan Studies, University of Kelaniya, Sri Lanka.

Ballantine J. (1997), The Sociology of Education: A Systematic Analysis, $4^{\text {th }}$ Edition, Prentice Hall Inc, USA.

Cole G. A. (1993), Personnel Management: Theory and Practice, $3^{\text {rd }}$ edition, Loader Jackson Printers, Arlesey, Bedfordshire, UK.

De Silva W. (1977), The Current Scene and Emerging Trends in Sri Lanka, the Universities, Education and Socio Economic Development of Sri Lanka, Sri Lanka Foundation Institute, Colombo.

Economic Review (1983), Higher Education, People's Bank, Colombo, Vol. 09, No. 1, April, pp. 03 -18.

Gunawardena C (1997), What Employers' Look in University Graduates, Economic Review, People's Bank, Colombo, Vol. 22, No. 10 Jan pp 19-22.

Hettige S. T. (2000), Students' Counselling and Welfare Service in the University System of Sri Lanka in Talent Development and Utilization, University of Kelaniya, Colombo.

Hommadi A. H. (1990), University in the third World, Perception in Planning and Management, Indian Publication Bureau, New Delhi, pp. 66-67.

Hugh et al (1992), Contemporary Issues in Sociology, McGraw-Hill Inc, New York.

Perera M. A. N. R. M. (2006), Education Problems in Sri Lanka, Paper presented at the National Conference on Economic Development, at Guru Nanak Dev University, Amritsar, India. 
Perera M. A. N. R. M. (2008), Impact of Socialization Agents on Students' Mental Health, Paper presented at Conference Conducted by the National Centre for Advanced Studies, University Grants Commission, Colombo.

Senadeera S. (1999), University Students' Educational Difficulties (in Sinhala medium), $2^{\text {nd }}$ edition, Chatura Publishers, Colombo.

Southern Provincial Council (1999), Unemployed Graduates, Southern Provincial Council Galle, Sri Lanka.

State Council of Sri Lanka (1942), Reports, Government Publications, p. 28.

University Act No.16 (1978), Government Publications, p.12.

University Grant Commission 1984 -1988, Reports, University Grant Commission, Colombo.

Wickramarachchi M. W. (2008), Employability of Management Graduates, Convocation Address, $35^{\text {th }}$ Convocation of the University of Sri Jayewardenepura, University of Sri Jayewardenepura, Colombo.

www.qaaacouncil.lk (accessed on 30.11.2008) 